\title{
Por uma abordagem intercultural da educação: levar a cultura a sério ${ }^{1}$
}

\section{Towards an intercultural approach of education: taking culture seriously}

\section{Tania Ogay}

Professora de Antropologia na Universidade de Fribourg, Suíça, na qual é responsável pelo programa Master de Educação intercultural e comparativa, dedica-se à pesquisa e aprofundamento dos processos de comunicação intercultural no contexto educacional, atualmente seus estudos estão concentrados na relação entre a escola e a família. FribourgSuíça.e-mail: tania.ogay@unifr.ch

\section{Resumo}

A importância de se considerar a dimensão cultural da educação é reconhecida cada vez mais não somente pelos investigadores e trabalhares da educação, mas também pelos responsáveis dos sistemas educativos. No entanto, nem sempre se sabe o que isso abrange precisamente. Este artigo procura refletir sobre as diferentes facetas da dimensão cultural

${ }^{1}$ Conferência proferida no Programa de Pós-Graduação em Educação da Pontifícia Universidade Católica do Paraná (PUCPR), em 25 de junho 2009, sob o título original em francês Pour une approche interculturelle de l'éducation: prendre la culture au sérieux. Tradução de Lindomar Wessler Boneti, PUCPR.

Rev. Diálogo Educ., Curitiba, v. 10, n. 30, p. 391-408, maio/ago. 2010 
da educação, bem como a respeito das armadilhas que o conceito de cultura, tão difícil de definir, pode ocultar. Procurando refutar o discurso universalista que nega ou minimiza a dimensão cultural, a educação intercultural utiliza um discurso que às vezes escorrega para o culturalismo, congelando a outra pessoa em diferenças imutáveis. Para evitar a escolha da sacralização das culturas, trata-se de conceber a interculturalidade como uma dialética entre o valor da diferença e o valor de igualdade. É então possível levar em conta a cultura e, por conseguinte, a diferença cultural, sem, no entanto, provocar um fator de divisão entre os seres humanos.

Palavras-chave: Educação. Educação intercultural. Cultura. Dialética.

\section{Abstract}

The importance of taking into account the cultural dimension of education is increasingly recognized by researchers and practitioners in education, but also by those responsible for educational systems. Yet one does not always know what it exactly means. This article presents a reflection on the various facets of the cultural dimension of education as well as on the pitfalls of the concept of culture, so difficult to define. In its effort to counter the universalist discourse that denies or minimizes the cultural dimension, intercultural education opposes a discourse that sometimes drifts into culturalism, fixing the Other in immutable differences. To avoid the pitfall of the sacralization of cultures, interculturality is to be conceived as a dialectic between the value of difference and the value of equality. It is then possible to take culture into account, and therefore cultural difference, but not as a factor of division among human beings.

Keywords: Education. Intercultural education. Culture. Dialectics.

\section{Introdução}

Nas últimas décadas, os especialistas da educação, investigadores e formadores, desenvolveram uma abordagem intercultural da educação (DASEN; PERREGAUX, 2000) frequentemente chamada de "educação 
intercultural". Apontando as ilusões e os riscos de uma concepção universalista da educação (que é apenas a expressão do etnocentrismo do grupo dominante, o qual considera a sua concepção da educação como normal e, por conseguinte, válida por toda a parte), esses investigadores e formadores chamaram a atenção da dimensão cultural na prática educativa, assim como na investigação sobre a educação. Nos últimos anos, pode-se dizer que o apelo desses especialistas e investigadores da educação começa a ser entendido em diversos níveis e instâncias de atuação no campo educacional. Assim, por exemplo, a Unesco estabeleceu Linhas e Diretrizes para a educação intercultural (2006) e o Conselho da Europa (2003) formulou uma Declaração da Conferência Permanente dos Ministros Europeus da Educação, intitulada "Educação intercultural: gestão da diversidade, reforço da democracia". Tomando-se o caso da Suíça, as instituições que formam os professores devem agora propor-lhes uma formação sobre as questões ligadas à interculturalidade (COHEP, 2007). Contudo, uma avaliação dessa formação (SIEBER; BISCHOFF, 2007) mostra que as práticas são muito diferentes de uma instituição para outra, destacando a falta de um verdadeiro conceito para a formação intercultural dos professores. As respostas dos formadores que participaram dessa avaliação revelam nomeadamente concepções muito diversas em relação aos conceitos de cultura e de interculturalidade e indicam que se as formações interculturais dos professores forem aplicadas aos futuros professores, o conteúdo e os objetivos destas são ainda pouco sensíveis. A proposta deste texto é estabelecer alguns parâmetros para uma abordagem da educação que tome a cultura seriamente, contemplando-a no contexto da sua complexidade.

\section{A dimensão cultural da educação}

$\mathrm{Na}$ vulgate da educação intercultural (retomando o termo de TAGUIEFF, 1988, quando fala do discurso do antirracismo), é habitual considerar que a dimensão cultural está presente no contexto da escola graças a alunos "de outras culturas", expressão inábil pela qual entende-se geralmente os alunos procedentes da imigração. No entanto, se se quer compreender a interculturalidade na escola, é preciso, igualmente, e talvez antes de tudo, refletir sobre a dimensão cultural da própria educação, da 
educação oferecida pela escola ou em outros contextos, principalmente no contexto familiar. Com efeito, a educação permite a transmissão da cultura, mas ela é também a sua expressão: os conteúdos da educação, da mesma maneira que a sua forma, são a expressão de certa cultura, são situados culturalmente, para retomar a expressão de Bruner (1996, p. 18):

Assim, a cultura, mesmo que seja um produto humano, dá forma, ao mesmo tempo que torna possível as atividades de um espírito especificamente humano. Nesta perspectiva, aprender e pensar continuam atividades situadas num quadro cultural, e dependem sempre da utilização de recursos culturais.

A dimensão cultural da educação comporta várias facetas. Retomando o triângulo pedagógico de Houssaye (2000), que examina as relações entre o aluno, o saber e o professor, pode-se distinguir três. A primeira é aquela da relação pedagógica entre o aluno e o professor. É provavelmente a que vem em primeiro lugar quando se interroga sobre a interculturalidade em educação: estudantes e professor podem referir-se a contextos culturais diferentes, os estudantes mais ou menos próximos da cultura do professor, bem como da cultura escolar que este geralmente absorve (os professores ainda, em grande parte, procedentes do grupo majoritário). A segunda faceta é aquela da relação entre o estudante e o saber, as estratégias de aprendizagem que o estudante se utiliza, a fim de se apropriar do saber que lhe propõe o professor. Essas estratégias de aprendizagem são igualmente situadas na cultura: de acordo com a inculturação (socialização inicial), a criança, ao chegar à escola, traz consigo uma bagagem cultural constituída de certas estratégias que lhe teriam sido incentivadas (pelos pais em especial) e outras até desencorajadas (por analogia com que mostram as investigações de psicologia intercultural comparada sobre o desenvolvimento cognitivo da criança: BERRY; Al, 1997b). Do mesmo modo, o que é considerado um saber digno a ser apreendido é relativo ao contexto cultural, o que é considerado como indispensável num contexto não o é necessariamente em outro. $\mathrm{O}$ saber aprendido na escola pode ser um saber que liga o professor e o aluno, tendo em comum um processo de aculturação similar, mas o saber pode igualmente separar o professor e o estudante, o caso extremo da escola colonial (GADJIGO, 1990). Isso nos conduz à terceira faceta da dimensão cultural da educação, aquela que vincula o professor com o saber. Assim, para além da reflexão que o 
professor deve conduzir sobre a ancoragem cultural dos estudantes por eles mesmos, é indispensável que tome consciência da ancoragem cultural do saber que quer ensinar, bem como das didáticas que utiliza.

É levando em conta essas três facetas da dimensão cultural da educação que o professor poderá realmente apreender os desafios postos pela interculturalidade da escola. Assim, adotar uma abordagem intercultural da escola implica:

1) Compreender a instituição "escola" como um produto de cultura e não como um universo virgem de qualquer ancoragem cultural;

2) levar em conta a relativamente grande congruência entre a cultura da escola e as dos seus diferentes atores (professores, alunos, pais de alunos);

3) criar um ambiente de aprendizagem que tenha o sentido de dirigir e reconhecer todos os atores, em especial: a) apoiar a descentração cultural dos professores, dos alunos e dos pais próximos da cultura escolar; b) apoiar a aculturação dos professores (no caso, cada vez mais frequente, onde os professores são procedentes de grupos culturais minoritários, MUJAWAMARIYA, 2002), e sobretudo a aculturação dos alunos e dos pais mais afastados da cultura escolar.

Antes que uma única "tomada de consideração da cultura dos alunos migrantes", quando é frequentemente posta em questão no vulgate da educação intercultural (que toma frequentemente a forma "de uma pedagogia couscous", ver ABDALLAH-PRETCEILLE, 1999), trata-se de realizar uma reflexão sistemática que não reduza a cultura somente a uma característica do outro, personificado pelo aluno procedente da imigração, mas que considera o conjunto do processo da educação na sua dimensão cultural e intercultural.

\section{As ciências da educação como um produto de cultura}

O fato de a educação estar ancorada num contexto cultural, situada culturalmente, infelizmente, com frequência, não é levado em consideração pelos investigadores em ciências da educação. As disciplinas científicas são 
igualmente produtos de cultura, mas de uma cultura ocidental, que pensa ser, geralmente, universal, esquecendo-se de questionar este preceito. Assim, Akkari (2000, p. 36) denuncia o que ele chama de etnocentrismo das ciências da educação:

O discurso dominante em ciências da educação é centrado igualmente na idéia indiscutível do indivíduo como único motor dos processos de educação e de formação. Ora, o individualismo é situado historicamente nas sociedades ocidentais onde verdadeiramente instalou-se a partir do desenvolvimento capitalista industrial, da modernização, da difusão do protestantismo e do retrocesso dos parâmetros tradicionais. O capitalismo industrial criou a ideia que os indivíduos podem escolher as suas trajetórias sociais, ser móveis geograficamente e ficar responsáveis de assegurar individualmente os seus rendimentos.

Na obra Pédagogies et pédagogues du Sud, Akkari e Dasen (2004) convidam seus colegas para se descentrar e se interessar pela contribuição dos outros contextos culturais que dão uma visão mais diferenciada da educação e da formação. Para Dasen em especial (2004), trata-se de realizar, pelas ciências da educação, o mesmo exame intercultural que ele e os seus colegas fizeram em relação à psicologia do desenvolvimento da criança (BERRY; Al, 1997a), a fim de levar em consideração o geral - válido para todos os contextos culturais e, assim, próprios à espécie humana - mas também o particular, isto é, o cultural, diferenciando-os, no entanto, por meio da pesquisa comparada. Trata-se assim de levar a cultura a sério na realização de qualquer investigação em ciências humanas, considerar a cultura mais do que ignorá-la:

[o comportamento humano] pode ser compreendido somente quando visto em seu contexto cultural. [...] Para compreender como cada um de nós vem a ser o que nós somos, devemos tomar em consideração o fato de que nossa herança biológica interage com nossas experiências, negociadas na maioria das vezes com os processos de socialização e de enculturação. Assim, um estudo do comportamento humano que ignore a cultura corre um grande risco (SEGALL et al., 1999, p. 23).

Tomando a psicologia social desta vez, cujo exame intercultural é mais recente e menos vasto que o da psicologia do desenvolvimento (OGAY, 2005), encontram-se várias investigações que 
permitem matizar as teorias até aqui apresentadas como universalmente válidas, por exemplo aquelas sobre os processos de atribuição social (MILLER, 2001). Para isso, os investigadores adotam em suas pesquisas, principalmente, a investigação comparada. Para que essas comparações tenham sentido, devem ser construídas de acordo com critérios teóricos e não como ocorre frequentemente, de acordo com critérios de conveniência ligados aos contatos preexistentes entre investigadores. No campo da comunicação intercultural, que se apoia muito sobre a psicologia social (GALLOIS; OGAY; GILES, 2005), esses critérios teóricos que permitem construir as comparações interculturais se dão frequentemente nas dimensões de variabilidade cultural, da maneira como foram definidas por Hall (1959; 1966), nomeadamente relacionada ao tempo (cronômetro) e ao espaço (proximidade), e ainda mais frequentemente às dimensões definidas por Hofstede (1980; 2001), em especial a dimensão individualismo-coletivismo.

As investigações interculturais comparativas atribuem assimà cultura a função de variável independente, ela antecede o processo investigação. Não considerando as fraquezas metodológicas de inúmeras investigações em comunicação intercultural, que comparam culturas supostamente coletivistas com culturas supostamente individualistas (OGAY, 2005), pode-se interrogar sobre a sua pertinência: muitas não têm explicitamente por objetivo a validação transcultural das teorias de comunicação intercultural e se satisfazem em descrever diferenças e semelhanças entre "culturas". Perguntamo-nos se as investigações dos papéis da cultura na comunicação entre pessoas referem-se a contextos culturais diferentes? Não muito, porque nessas investigações a cultura é reduzida a um simples critério de categorização dos indivíduos, não é dinâmica, é bloqueada. Além disso, essas investigações arriscam transmitir a ideia que os sistemas culturais são estáveis ou mesmo imutáveis (pois, diferentemente, não seriam comparáveis). Ainda, apontando continuamente sobre as diferenças entre as culturas, esse tipo de investigação intercultural dá a impressão de haver diferenças radicais e insuperáveis entre os grupos culturais e, por conseguinte, de incomunicabilidade.

Ao lado das investigações comparativas - que guardam a sua razão de ser, se têm explicitamente como objetivo examinar a validade transcultural das teorias formuladas num contexto cultural específico - eu privilegio uma investigação intercultural que considera a cultura não como um antecedente, mas como um processo, na essência da interrogação do investigador. Para além da constatação das semelhanças e diferenças, trata-se de atribuir um 
papel ativo à cultura, procurando compreender como essas diferenças culturais constroem-se e são compreendidas pelos que com elas interagem, como a cultura interage com os processos físico-sociais, notadamente-para retornar à educação - no contexto do ensino-aprendizagem.

\section{Ainda e sempre o conceito de cultura}

A grande dificuldade que encontram as abordagens interculturais da educação tem origem nos dois conceitos centrais, a cultura e a educação, como conceitos particularmente difíceis de apreender. Ambos podem ser tomados quer em sentido estrito, quer em sentido amplo. $\mathrm{Na}$ concepção restrita, a educação é considerada sinônimo de escola, e a cultura uma soma de características objetivas que definem um grupo cultural (representado, geralmente, de maneira demasiadamente simplista, como um grupo de pessoas imigrantes). Na concepção ampla, sustentada notadamente por Dasen (2004), a educação é compreendida como a transmissão da cultura na escola, mas igualmente em qualquer outro contexto no qual pode acontecer essa transmissão da cultura. Quanto à cultura, é compreendida como um conjunto de significados compartilhados e continuamente reinterpretados por uma comunidade de indivíduos. Mais interessante que a primeira, essa concepção ampla dos dois conceitos centrais das abordagens interculturais da educação coloca-nos, contudo, problemas: assim, tudo ou quase tudo seria da competência da educação e da cultura (OGAY; Al, no prelo).

Como considera Cuche (1996), a cultura é um conceito indispensável para poder pensar a unidade da humanidade na sua diversidade: se os grupos humanos são diferentes, não é porque constituem raças diferentes e seriam, por conseguinte, geneticamente diferentes, como pretendiam as teorias raciais, mas porque, vivendo em ambientes diferentes, desenvolveram modos de fazer e significados diferentes. A cultura é, assim, o conceito central da antropologia. No entanto, continua sendo difícil defini-la, mesmo sendo numerosos os autores que tentaram. Assim, Kroeber e Kluckhohn (1952) tinham identificado 160 definições e, mais de meio século mais tarde, Baldwin, Faulkner, Hecht, e Lindsley (2006) encontraram 313 definições suplementares. Se é necessário escolher apenas uma só, reiterei a formulada por Camilleri: 
a cultura é o conjunto mais ou menos unificado dos significados adquiridos e mais persistentes, e os mais compartilhados pelos membros de um grupo, a partir da filiação a este grupo, são levados a distribuir de maneira prevalente a partir dos estímulos que provêm do ambiente e deles mesmos, induzindo no que diz respeito estes a estímulos, atitudes, representações e comportamentos comuns valorizados, dos quais tendem a assegurar a reprodução por vias não genéticas (CAMILLERI apud VINSONNEAU, 1997, p. 54).

É mais fácil compreender aquilo que é a cultura, aquilo que ela traz para nossa vida diária, quando nos falta. Assim, seria possível dizer, de maneira um pouco lapidar talvez, que a cultura é algo que falta ao indivíduo quando ele se encontra num ambiente desconhecido. Esses significados compartilhados são referências comuns que permitem a uma comunidade de indivíduos viver juntos num contexto ecológico dado. Com efeito, como formula o quadro teórico ecocultural (BERRY, 1971), a cultura resulta do esforço de um grupo de humanos para adaptar-se ao contexto ecológico do seu ambiente (social e ecológico). A cultura é, por conseguinte, dinâmica e não estática, do contrário não teria essa função adaptativa. Ting-Toomey (1999) acrescenta ainda quatro funções da cultura: em primeiro lugar, fornecendo ao indivíduo um quadro de referência (por exemplo, valores e normas que definem como é suposto comportar-se uma "boa pessoa"), permite-lhe definir e manter a sua identidade. Assim, a cultura compartilhada permite sentir a inclusão ao grupo, o que satisfaz a nossa necessidade de pertença e permite-nos sentir a segurança e a aceitação. Mas, ao mesmo tempo, essa identificação ao grupo faz-nos sentir as diferenças em relação aos outros grupos: a cultura serve igualmente à regulação das fronteiras entre os grupos, orienta-nos nas nossas percepções do endogrupo e do exogrupo. Assim, se ela nos conforta na nossa identidade e nos tranquiliza, a cultura limita também o nosso campo de visão, alimenta as nossas atitudes e comportamentos etnocêntricos (razão pela qual a formação intercultural terá como centralidade favorecer a decentração cultural). A última função da cultura que menciona Ting-Toomey (1999) é a da comunicação, central para a educação: em primeiro lugar, é a cultura que dá forma à comunicação, e que nos indica como comunicar (o código linguístico a utilizar, certamente, mas igualmente o quê dizer, a quem, quando e como). A cultura fornece, assim, um guia para realizar 
a interação com pessoas da mesma comunidade cultural mas também com pessoas de outras culturas, vincula os indivíduos entre si por meio dos códigos, normas e certificados de interação compartilhados. É pela comunicação que a cultura é transmitida e continuamente reinterpretada.

\section{Qualquer situação intergrupo é intercultural?}

Um aspecto que, a meu ver, nunca é discutido na literatura da educação ou da comunicação interculturais, e que então causa sofríveis confusões, é: quando se pode falar de culturas e, por conseguinte, de intercultural? Camilleri, na sua definição da cultura, liga-a simplesmente a um grupo ao qual os indivíduos são filiados. Mas de qual grupo se trata e em qual escala? Com efeito, o que reúne um grupo de indivíduos que, pelo fato de comunicar juntos, desenvolvem significados compartilhados, pode ser pensado em diversos níveis: pode tratar-se de um bairro, uma cidade, uma região, um país? Mas também de uma instituição (uma escola)? De um grupo profissional como o dos professores do ensino fundamental que desenvolveriam uma cultura que os distinguiria dos professores do ensino médio?

Considera-se que é relevante falar de cultura para os diferentes grupos sociais, o que significaria dizer que é intercultural qualquer situação que implica grupos sociais diferentes. Tal abertura da definição coloca problemas para a identidade, por conseguinte, a especificidade da investigação intercultural, como a antropologia: querendo ser tudo, acaba por não ser nada. Esse questionamento a respeito do limite do conceito de cultura é evocado igualmente por Cuche (1996):

Nos dias de hoje, não importa o grupo social, pode reivindicar uma cultura própria. Qualquer forma de expressão coletiva torna-se "cultura". A cultura se fragmenta, a cultura se torna migalhas. Evoca-se, assim, por exemplo, "cultura hip hop", "a cultura futebolística" e, de maneira ainda mais contestável, "a cultura dos micro-ondas", "a cultura do telefone celular". Ora, estas práticas e o que elas implicam não podem ser assimiladas a estes sistemas globais de interpretação do mundo e estruturação dos comportamentos que correspondem ao que a antropologia entende por "cultura" (CUCHE, 1996, p. 96). 
Parece-me assim importante não reduzir a dimensão cultural à dimensão grupal, que é o objeto da psicologia social das relações intergrupais (que, precisamente, não se levou muito em conta o fato que se estudava grupos sociais inseridos em contextos culturais geralmente ocidentais). A cultura no sentido antropológico do termo implica certo contexto (espacial, mas também temporal e simbólico) no qual vive uma comunidade de indivíduos, que desenvolve, transmite e transforma diferentes instrumentos culturais para gerir a sua vida comum e as suas relações com as outras comunidades. Quando são formalizados, esses instrumentos culturais vinculam frequentemente a cultura a um território. Quando as regras para a vida em comum são formalizadas em leis, a validade destas é geralmente vinculada a um território. Existem diferentes níveis de territórios mais ou menos vinculados: pensa-se talvez em primeiro lugar no território de um Estado na acepção de um país, mas este território pode também ser supranacional - como a União Europeia -, ou então dentro de um país: regional, estadual, comunal. Assim, quando a educação é formalizada num sistema educativo, o alcance deste, tão importante para a transmissão da cultura, é geralmente ligado a um território (exceto no caso do ensino superior transnacional, em forte desenvolvimento nos últimos anos, que substitui a mobilidade dos estudantes pela mobilidade dos programas e os formadores, ver a este respeito, KNIGHT, 2008). Se o alcance dos meios de comunicação social é, em contrapartida, menos estreitamente ligado a um território como o da educação formal, eles, no entanto, participam largamente na homogeneização interna e na diferenciação com os outros grupos culturais, por conseguinte, na formação e transformação das diferentes culturas.

Esta comunidade cultural própria é atravessada por diferentes dimensões de variabilidade, responsáveis pela impermutabilidade dos indivíduos, embora referindo-se à mesma cultura: diferenças de tipo, de gerações, de nível socioeconômico, de hábitat (rural-urbano, plano-montanha), de grupo profissional, etc. Todas as diferenças internas são interpretadas no âmbito da cultura comum de referência. A cultura não é uma dimensão de variabilidade entre outros (o que frequentemente é apresentado assim quando se interroga se um fenômeno observado for explicado pela cultura, o tipo, ou o nível socioeconômico). Pelo contrário, a cultura é o quadro geral no qual tomam sentido as outras dimensões de diferenças entre os grupos sociais e os indivíduos porque estes se referem mesmo a um contexto cultural. $\mathrm{O}$ 
que não o impede de se referir igualmente às outras culturas, em função da sua história pessoal e familiar, notadamente quando houve migração. Assim, quando um indivíduo troca o seu contexto cultural por outro, surge um conjunto de significados culturais, entre os quais uma maneira de gerir as relações entre homens e mulheres (um tema que retorna frequentemente nas situações interculturais trazidas por professores em formação). Se o seu comportamento com pessoas do sexo oposto intriga na sociedade de acolhimento, não há muito sentido em querer separar a dimensão tipo da dimensão cultural, questionando se este indivíduo age assim "porque é de outra cultura", ou "porque é um homem". Portanto, a maneira de conceber as relações entre os sexos é precisamente um desses significados produzidos pela cultura, e é situada culturalmente (o que talvez não tenha sido visto ou considerado por certas feministas ocidentais, é que sua visão a respeito das relações entre os sexos era compartilhada pelas mulheres do mundo inteiro).

\section{Levar a cultura a sério sem, contudo, vê-la como uma tragédia}

Uma escolha importante ameaça todos os investigadores e trabalhadores da educação, desejosos por tratar a cultura seriamente: a de tomar a cultura demasiadamente a sério, ou mesmo tragicamente. Confrontados pelo discurso indivíduo-universalista (de acordo com o termo de TAGUIEFF, 1988), que nega a dimensão cultural para não considerar que os indivíduos, todos singulares e reunidos na mesma espécie humana, correm o risco de adotar um discurso culturalista. Esse discurso que, na força da insistência para se considerar a cultura, vem reduzir o indivíduo "à sua cultura" (como se a pertença à uma cultura fosse uma evidência, assim como sê-lo-ia para certos a pertença à uma raça), aumenta o que Camilleri (1990) chama de sacralização das culturas. Quando a cultura é pensada como da ordem do consagrado, ela insere os indivíduos nas suas diferenças imutáveis (hétero-atribuídos, mas também autoatribuídos). As culturas tornam-se constrangimentos rígidos que fecham os indivíduos sem nenhuma margem de manobra e passam a ser totalmente sujeitos “à cultura deles": "eu faço/ele faz isso, porque é minha/ sua cultura. É assim mesmo, isso foi sempre assim e permanecerá assim”.

No sentido de se opor a essa derivação que mata no ovo qualquer comunicação intercultural, Camilleri (1990) assinala quatro pontos: para começar, trata-se de mostrar que as culturas não são absolutas, mas formações 
sempre provisórias, que resultam de um processo histórico de adaptação ao ambiente e às necessidades dos homens (encontra-se aqui a função adaptativa da cultura no meio do quadro teórico eco-cultural de BERRY, 1971). Trata-se igualmente de fazer compreender que o homem não se reduz à cultura que adquiriu pelo processo de inculturação. Pelo contrário, põe sobre esta cultura o seu olhar de ator singular, portador de uma história que lhe é própria. A cultura é um repertório que cada indivíduo interpreta à sua maneira, em função da sua própria sensibilidade, do seu percurso na vida. Barmeyer (2007) traça um paralelo com a língua: ter uma língua comum não quer dizer, portanto, que vai se falar de maneira idêntica, e a possibilidade de pensar a mesma coisa é ainda menor. Camilleri (1990, p. 16-17) recomenda igualmente indicar "o discurso crítico que se desenvolveu sobre os limites do cultural e as suas utilizações perversas pelas sociedades, os estados e os subgrupos sociais". Finalmente, o autor insiste na necessidade de promover uma atitude reflexiva que permita-nos estar ligados ao nosso sistema cultural sem, no entanto, sermos sujeito dele, e de ter assim uma posição "emergida em vez de continuar a ser imergida". Camilleri termina seu artigo com este parágrafo, o qual capta maravilhosamente a complexidade do intercultural:

Há, por conseguinte, um movimento dialético que consegue manter o intercultural: assegurar o respeito das culturas, mas no âmbito de um complexo de atitudes que autorizam a sua superação; dar aos pertences as condições necessárias para perceber a sua cultura como legítima e ascender ao sentimento fundamental de ser reconhecidos e, ao mesmo tempo, ter a liberdade de se posicionar sem culpabilização relativamente aos sistemas que o cercam. Isto de forma a elaborar eventualmente a sua fórmula cultural individual. É uma das maneiras pelas quais os grupos interculturais podem tornar-se uma matriz de criatividade cultural (CAMILLERI, 1990, p. 17).

A dialética do interculturalidade, levando em consideração a cultura, sem, no entanto, provocar um fator de divisão entre os seres humanos, foi posta de forma notável por Edelmann (2007), numa investigação qualitativa que investiga qual é a competência profissional dos professores interrogada pela diversidade cultural ligada às migrações internacionais. Inspirando-se no quadro dialético de valores de Helwig (1967) e de Schulz von Thun (1997), Edelmann (2007) desenvolveu o quadro dialético da diferença, fundado sobre os valores da igualdade e da diferença. O quadro dialético dos valores 
se apoia na ideia de que, para poder ser construtivo, qualquer valor deve ser contrabalançado em relação a seu contrário. Por exemplo, o valor da liberdade tem necessidade de ser contido pelo valor da solidariedade, sem aquele, a porta estaria aberta para a entrada do egoísmo dominador. O valor contrário permite criar um equilíbrio, não se trata de uma contradição que seria necessário resolver, mas da tensão positiva que forma uma dialética. Esta, ou mais precisamente a dialógica de acordo com o termo privilegiado por Morin (1990, p. 99), encontra-se na essência do pensamento complexo: "O princípio dialógico permite-nos manter a dualidade na unidade. Associa dois termos ao mesmo tempo complementares e antagônicos". Na dialética da interculturalidade, como a formula Edelmann (2007), o valor da igualdade - que reconhece igualmente o valor e a dignidade de qualquer ser humano, sem distinções ligadas às pertenças sociais - deve ser contrabalançado pelo valor da diferença - que reconhece a legitimidade para qualquer indivíduo, referindo-se a uma cultura compartilhada num grupo, diferenciando-o dos outros grupos. Exagerar o valor da igualdade conduz à ignorância da diferença cultural e ao assimilacionismo. Reencontra-se então o indivíduouniversalismo de Taguieff (1988), já mencionado anteriormente. Uma ilustração é o discurso frequente dos professores, constatado notadamente por Edelmann (2007), mas também visto em outros contextos culturais, como, por exemplo, nos Estados Unidos, por Mahon (2006), que dizem procurar, sobretudo, não fazer diferenças entre os seus alunos, afirmando que os tratam exatamente da mesma maneira.

Como visto neste texto, a educação intercultural construiu-se em resposta ao universalismo etnocêntrico homogeneizante que não reconhece a dimensão cultural na educação. Propondo tomar seriamente a cultura na educação, a abordagem da educação intercultural traz o polo oposto do valor de igualdade na educação e permite um equilíbrio. A condição, contudo, é de não tomar a cultura ao trágico e de superar então esse exagero do valor da diferença que é o culturalismo, a sacralização das culturas, denunciado por Camilleri (1990).

\section{Conclusão}

Levar a cultura a sério é indispensável para a reflexão sobre a educação em toda a sua complexidade. Isso exige um reconhecimento 
da diversidade das culturas no âmbito da humanidade que corresponde a uma diversidade de conceitos da educação. Mas quem diz diversidade de culturas, diz igualmente diferença cultural (se podemos falar de diversidade de culturas é porque percebemos diferenças entre as culturas). Ora, este conceito é escorregadio e suscita, com razão, muita desconfiança. Quando nos entusiasmamos diante da riqueza da diversidade cultural, nos mostramos hesitantes se colocada a questão das diferenças culturais, fechando-nos, então, em um discurso contraditório, passando da valorização da diversidade das culturas para a minimização da diferença cultural (OGAY, 2000; 2006). Isso porque o conceito de diferença cultural é visto como uma ameaça ao valor da unidade e da igualdade do gênero humano. É o que acontece com um certo discurso intercultural que, exigindo com força "o respeito da cultura", faz dela uma nova prisão para os indivíduos. Torna-se, assim, essencial ter um conceito dinâmico de cultura, aliando continuidade e mudança, que forneça ao indivíduo um repertório de significados, mas que não o aprisione a um programa ao qual ele seria submisso. Sobretudo, é indispensável para nós - professores e pesquisadores - reconhecermos nossas ambivalências diante das diferenças culturais, compreendê-las e explicitá-las não como uma contradição a ser resolvida, mas como uma dialética que fundamenta a interculturalidade.

\section{Referências}

ABDALLAH-PRETCEILLE, M. L'éducation interculturelle. Paris: PUF, 1999.

AKKARI, A.-J. Au-delà de l'ethnocentrisme en sciences de l'éducation. In: DASEN, P.; PERREGAUX, C. (Org.). Pourquoi des approches interculturelles en sciences de l'éducation? Bruxelles: De Boeck, 2000. p. 31-48.

AKKARI, A.; DASEN, P. R. (Org.). Pédagogies et pédagogues du Sud. Paris: L'Harmattan, 2004.

BALDWIN, J. R. et al. Redefining culture: perspectives across the disciplines. Mahwah NJ: Routledge, 2006.

BARMEYER, C. Management interculturel et styles d'apprentissage: etudiants et dirigeants en France, en Allemagne et au Québec. Québec: Les Presses de l’Université Laval, 2007.

Rev. Diálogo Educ., Curitiba, v. 10, n. 30, p. 391-408, maio/ago. 2010 
BERRY, J. W. Ecological and cultural factors in spatial perceptual development. Canadian Journal of Behavioural Science, v. 3, n. 4, p. 324-336, 1971.

BERRY, J. W. et al. (Org.). Handbook of cross-cultural psychology. 2nd ed. Boston: Allyn \& Bacon, 1997a.

. Handbook of cross-cultural psychology: basic processes and human development. 2nd ed. Boston: Allyn \& Bacon, 1997b.

BRUNER, J. L'éducation, entrée dans la culture: les problèmes de l'école à la lumière de la psychologie culturelle. Paris: Retz, 1996.

CAMILLERI, C. Les conditions de l'interculturel. Intercultures, n. 9, p. 11-17, 1990.

CONFÉRENCE SUISSE DES RECTRICES ET RECTEURS DES HAUTES ÉCOLES PÉDAGOGIQUES - COHEP. Recommandations relatives à la formation des enseignantes et enseignants aux approches interculturelles. Berne: COHEP, 2007.

CONFÉRENCE PERMANENTE DES MINISTRES EUROPÉENS DE L'ÉDUCATION. Education interculturelle: gestion de la diversité, renforcement de la démocratie. Strasbourg: Conférence permanente des ministres européens de l'éducation, 2003.

CUCHE, D. La notion de culture dans les sciences sociales. Paris: La Découverte, 1996.

DASEN, P. R. Education informelle et processus d'apprentissage. In: AKKARI, A.; ASEN, P. R. (Org.). Pédagogies et pédagogues du Sud. Paris: L’Harmattan, 2004. p. 23-52.

DASEN, P. R.; PERREGAUX, C. (Org.). Pourquoi des approches interculturelles en sciences de l'éducation? Bruxelles: De Boeck Université, 2000.

EDELMANN, D. Pädagogische professionalität im transnationalen sozialen Raum. Eine qualitative untersuchung über den umgang von lehrpersonen mit der migrationsbedingten heterogenität ihrer klassen. Wien Zürich: LIT, 2007.

GADJIGO, S. Ecole blanche, Afrique noire: l'école coloniale dans le roman d'Afrique noire francophone. Paris: L'Harmattan, 1990.

GALLOIS, C.; OGAY, T.; GILES, H. Communication accommodation theory: a look back and a look ahead. In: GUDYKUNST, W. B. (Org.). Theorizing about intercultural communication. Thousand Oaks: Sage, 2005. p. 121-148. 
HALL, E. T. The silent language. New York: Doubleday, 1959.

. The hidden dimension. New York: Doubleday, 1966.

HELWIG, P. Charakterologie. Freiburg: Herder, 1967.

HOFSTEDE, G. Culture's consequences: international differences in workrelated values. Beverly Hills, CA: Sage, 1980.

. Culture's consequences: comparing values, behaviors, institutions and organizations across nations. 2nd ed. Thousand Oaks, CA: Sage, 2001.

HOUSSAYE, J. Théorie et pratiques de l'éducation scolaire: le triangle pédagogique. 3e éd. Berne: Peter Lang, 2000.

KNIGHT, J. Enseignement supérieur transnational: introduction. In: L'ORGANISATION POUR COOPERATION ET DEVELOPPEMENT ECONOMIQUE - l'OCDE. (Org.). L'enseignement supérieur transnational: un levier pour le développement. Paris: l'OCDE, 2008. p. 23-53.

KROEBER, A. L.; KLUCKHOHN, C. K. Culture: a critical review of concept and definitions. Cambridge, MA: Harvard University Press, 1952.

MAHON, J. Under the invisibility cloak? Teacher understanding of cultural difference. Intercultural Education, v. 17, n. 4, p. 391-405, 2006.

MILLER, J. G. The cultural grounding of social psychological theory. In: TESSER, A.; SCHWARZ, N. (Org.). Blackwell Handbook of social psychology: Intraindividual processes. Malden, MA: Blackwell, 2001. p. 22-43.

MORIN, E. Introduction à la pensée complexe. Paris: ESF, 1990.

MUJAWAMARIYA, D. (Ed.). L'intégration des minorités visibles et ethnoculturelles dans la profession enseignante. Outremont (Québec): Logiques, 2002.

OGAY, T. De la compétence à la dynamique interculturelles. Des théories de la communication interculturelle à l'épreuve d'un échange de jeunes entre Suisse romande et alémanique. Berne: Peter Lang, 2000.

. Comment prendre en compte la culture sans la figer? A la recherche d'une approche dynamique de la culture et de son interaction avec les processus psychosociaux. Analele Stiintifice ale Universitatii Â «Al. I. Cuza Â», sectiunea Stiintele Educatiei, n. 9, p. 39-48, 2005. 
Ecoles de ville et écoles de campagne, une entrée pour parler des différences culturelles avec les enseignants. Premières analyses d'une recherche longitudinale auprès d'étudiants en formation initiale d'enseignants. Formation et pratiques d'enseignants en questions. Revue des HEP de Suisse romande et du Tessin, v. 4, p. 35-53, 2006.

OGAY, T.; et al. Dadas et marottes de la recherche en éducation interculturelle: Que cherchent les chercheurs? In: THÉSÉE, G.; CARIGNAN, N.; CARR, P. (Ed.). Les faces cachées de la recherche interculturelle. Paris: L'Harmattan, sous presse.

SCHULZ VON THUN, F. Miteinander reden: stile, werte und Persönlichkeitsentwicklung. Reinbek: Rowohlt, 1997.

SEGALL, M. H. et al. Human behavior in global perspective: an introduction to cross-cultural psychology. 2nd ed. Boston: Allyn \& Bacon, 1999.

SIEBER, P.; BISCHOFF, S. Rapport. Examen de la situation actuelle de la pédagogie interculturelle au sein des hautes écoles pédagogiques et des établissements de formation des enseignants de Suisse. Berne: Conférence suisse des rectrices et recteurs des hautes écoles pédagogiques, 2007.

TAGUIEFF, P-A. La force du préjugé: essai sur le racisme et ses doubles. Paris: La Découverte, 1988.

TING-TOOMEY, S. Communicating across cultures. New York: Guilford, 1999. UNITED NATIONS EDUCATIONAL, SCIENTIFIC AND CULTURAL ORGANIZATION - UNESCO. UNESCO guidelines on intercultural education. Paris: Unesco, 2006. Disponível em: <http://unesdoc.unesco.org/ images/0014/001478/147878e.pdf>. Acesso em: 10 abr. 2009.

VINSONNEAU, G. Culture et comportement. Paris: Armand Colin, 1997.

Recebido: 22/04/2009

Received: 04/22/2009

Aprovado: 22/05/2009

Approved: 05/22/2009 